\title{
Horse phenotyping based on video image analysis of jumping performance for conservation breeding
}

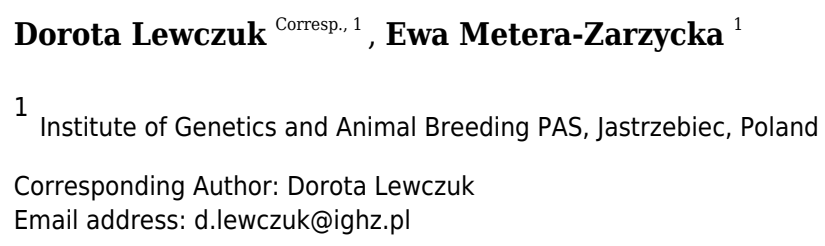

Background: Many horse breeds in the world are reserved as genetic resources; however, their characteristics seem to be insufficiently clarified, especially in terms of horse performance. Two jumping ability evaluation methods have been used to compare different types of performance breeds and on this basis their applicability for precision phenotyping has been determined. Methods: Jumping data of 186 young Polish Warmblood stallions (27 with an endangered status) bred for sport and multipurpose use was collected during their performance tests organised under identical environmental conditions following the same guidelines. Jumping data consisted of objective measurements of free jumping parameters and the marks for jumping. Video recordings of 514 jumps (73 records for 27 stallions with an endangered status) were collected using a digital Panasonic AG-EZ 35 camera ( $25 \mathrm{fr} / \mathrm{sec}$ ). Filming was recorded during a free jumping test in the line on a doublebarre obstacle $(100-120 \mathrm{~cm} \times 100 \mathrm{~cm})$. Spatial and temporal variables of the jump were measured. The analysis of variance was performed (SAS, General Linear Model and Mixed procedures) using the statistical model, which included the random effect of the horse and fixed effects of the year of test, breeding status, height of jump and the successive number of the jump for objective kinematic data. The fixed effects of the year of test and breeding status were included in the model for subjective performance test data. Results: Performance marks for free jumping were lower in the endangered group of stallions in the trainers' opinion ( $p \leq 0.05)$, while no statistically significant differences were found in the judges' opinions. Statistically significant differences in jumping variables were measured for the bascule points - the elevations of the withers and croup were higher in the endangered group ( $p \leq 0.001)$ and the take-off time was prolonged ( $p \leq 0.05)$, which explained the subjective evaluation. Discussion: The use of objective evaluation methods provides important information for practice, as phenotypic differences between horses may be unclear in the subjective evaluation. The objective evaluation should be used to characterise the performance potential of different breeds, because the information from the evaluators might not be consistent. Such 
characteristics should be recorded at least for every new population. 
1 Horse phenotyping based on video image analysis of jumping performance for 2 conservation breeding

3

4 D.Lewczuk $^{1 *}$, E.Metera-Zarzycka ${ }^{1}$

$5{ }^{1}$ Institute of Genetics and Animal Breeding PAS Jastrzębiec, ul. Postępu 36A, 05-552

6 Magdalenka, Poland

7

$8 \quad$ *corresponding author: D.Lewczuk@ighz.pl

9

10

11

12 
14 Abstract

15 Background: Many horse breeds in the world are reserved as genetic resources; however, their 16 characteristics seem to be insufficiently clarified, especially in terms of horse performance. Two 17 jumping ability evaluation methods have been used to compare different types of performance 18 breeds and on this basis their applicability for precision phenotyping has been determined.

19 Methods: Jumping data of 186 young Polish Warmblood stallions (27 with an endangered status) bred for sport and multipurpose use was collected during their performance tests organised under identical environmental conditions following the same guidelines. Jumping data consisted of objective measurements of free jumping parameters and the marks for jumping. Video recordings of 514 jumps (73 records for 27 stallions with an endangered status) were collected using a digital Panasonic AG-EZ 35 camera (25 fr/sec). Filming was recorded during a free jumping test in the line on a doublebarre obstacle $(100-120 \mathrm{~cm}$ x $100 \mathrm{~cm})$. Spatial and temporal variables of the jump were measured. The analysis of variance was performed (SAS, General Linear Model and Mixed procedures) using the statistical model, which included the random effect of the horse and fixed effects of the year of test, breeding status, height of jump and the successive number of the jump for objective kinematic data. The fixed effects of the year of test and breeding status were included in the model for subjective performance test data.

Results: Performance marks for free jumping were lower in the endangered group of stallions in the trainers' opinion $(\mathrm{p} \leq 0.05)$, while no statistically significant differences were found in the judges' opinions. Statistically significant differences in jumping variables were measured for the bascule points - the elevations of the withers and croup were higher in the endangered group $(\mathrm{p} \leq 0.001)$ and the take-off time was prolonged $(\mathrm{p} \leq 0.05)$, which explained the subjective evaluation.

Discussion: The use of objective evaluation methods provides important information for practice, as phenotypic differences between horses may be unclear in the subjective evaluation. The objective evaluation should be used to characterise the performance potential of different breeds, because the information from the evaluators might not be consistent. Such characteristics should be recorded at least for every new population. 


\section{Introduction}

Horse genetic resources play an important role in horse breeding worldwide. Most horse breeds traditionally kept to preserve their historical, regional and local utility value act as gene pools in the case of a breeding crisis. An inbreeding depression can be a problem not only in small, closed populations, but also in large populations of closely related animals. Increased homozygosity in highly selected animals not only causes inbreeding depression (Charlesworth \& Willis 2009), but also fitness problems (Leroy, 2014). While it may not be an issue in current Warmblood horse breeding (Borowska \& Szwaczkowski 2015, Pikuła et al. 2017), several endangered subpopulations have been established as gene pools. Introduction of genetically unrelated horses within the same performance type would be the first step to follow in the case of inbreeding depression. Therefore, various horse breeds are preserved as national genetic resources (ERFP 2014). These include animals of a local traditional performance type such as the Lusitano (Vincente, 2012), old classical dressage horses such as the Menorca or Iberian (Solé et al. 2013a, Solé et al. 2013b, Valera et al. 2013), carriage horses e.g. the Lipizzaners (Curik, 2003) or Kladrubers (Vostrá-Vydrová et al. 2016) and others, such as e.g. the Finnhorse (Sairanen et al. 2009), Sorraia (Kjöllerström et al. 2015) or Friesian horses (Ducro et al. 2006). It seems necessary to monitor not only the genetic distance and genetic parameters of these populations, but also their usability and differences in performance. Such monitoring seems especially important for breeds kept as multipurpose genetic resources in relation to highly specialised sport populations (ERFP, 2014) such as the Tori horse from Estonia, the Napoletano from Italy, the Slovak Warmblood from Slovakia, the Gelder from the Netherlands or the Polish Małopolski and Wielkopolski subpopulations. New evaluation methods may improve the assessment of horse performance and consequently find applications in characterising endangered populations (Kristjansson et al. 2013, Solé et al. 2013c, Kristjansson et al. 2016). Studies mentioned above focused on gait characteristics, while the aim of the presented study is to characterise jumping performance based on video image analysis of horse breeds differing in terms of their endangered status and skills. Objectively measured jumping variables and subjective marks given by judges were used to test the hypothesis that the objective method will ensure more precision phenotyping of horses in terms of their jumping skills and will provide insight into jumping characteristics of endangered horses. Several attempts have been made in horse selection to monitor jumping characteristics of different breeds (Lewczuk 2008, Janczarek 
76 2011); however, objective video image analysis (VIA) has never been used to monitor or 77 compare endangered horse characteristics. The unique character of Polish tests gave such a 78 possibility and facilitated a discussion of horse jumping skills. Both groups of the investigated 79 horses are expected to be performance horses, the "non-endangered" population on a high sport 80 competition level and the "endangered" on an overall riding and recreational level, thus 81 differences between their jumping skills should be clearly visible. The phenotype description 82 will also be compared using correlation analyses.

83

84 Material \& Methods

Performance data were collected for 3-year old stallions, of which 159 were registered as 86 sport breed Warmblood and 27 stallions of the endangered Wielkopolski and Małopolski subpopulations. All the horses were tested during the same 100-day performance tests at two training centres and the investigations were carried out over a period of three years. Horses were filmed in free jumping during the performance tests in order to measure jumping parameters and they were evaluated during their performance tests by the trainer, the judging committee and riders being specialists in their jumping discipline. According to the Polish law (3rd Ethical Local Commission Warsaw, Poland) observational research on practical procedures does not require any special approval. Free jumping was organized according to the scheme for performance tests of the Polish Horse Breeders Association - PHBA (www.pzhk.pl) on the final test day. A total of 514 jumps were recorded using Panasonic AG-EZ 35 ( $25 \mathrm{fr} / \mathrm{sec})$ digital equipment, filming the third and last obstacle of a jumping line during the official performance test. The camera was standing in the same position 10 meters from the horse pathway in the line of the obstacle centre. The filmed doublebarre obstacle was 100-120 cm high and $100 \mathrm{~cm}$ wide. The jumping line started with a ground pole, followed by two vertical obstacles of $50 \mathrm{~cm}$ and 65 $\mathrm{cm}$ in height. The distances between the obstacles were as follows: a pole on the ground $2.5 \mathrm{~m}$

101 before the first vertical, then 5.8-6.5 m before verticals and 5.8-7 $\mathrm{m}$ before the last filmed 102 obstacle. The following jumping variables were measured on the frames of the films:

103 1. distances of take-off (the last full contact of both hind hooves before the airborne phase)

104 and landing (the first full contact of both front hooves after the airborne phase);

105 2. distances of lifting for each limb (from the highest point of the pole to the lowest point of 106 the hoof) 
107 3. distances of elevation of the head, withers and croup (the highest points of these body parts on the "bascule" frame, where the withers are the highest body part in relation to the

1104 4 the angle of the head on the "bascule" frame (between the line of the nose and the line perpendicular to the ground);

1125 . the time of take-off and landing and the total time of the jump (the number of frames).

113 Spatial measurements were obtained using the manual program for image analysis developed by

114 Cytowski (the Institute of Computer Science of the Polish Academy of Science) and temporal 115 measurements by Motion DV Panasonic. The calibration for linear measurements was performed 116 by measuring the distances between static marks on the ground on the horse jumping line.

117 Subjective judgment notes of the performance test results were obtained from the Polish

118 Horse Breeders Association database. The performance test data consisted of jumping notes in a 119 scale from 0 (very bad) to 10 points (excellent) for the following traits:

120 1. free jumping and jumping under the rider (as judged by the trainer and judges);

121 2. trainability (evaluated by the trainer);

122 3. rideability for jumping (evaluated by experienced riders hired for the test).

123 The obtained results were analysed statistically by the analysis of variance (Statistical Analysis 124 Software; General Linear Mean and Mixed procedures). The statistical model for the objective 125 data included the random effect of the horse and fixed effects of the status of breed 126 (endangered/non-endangered), year of test, height of obstacle and the successive number of jump 127 over the obstacle. The statistical model for the subjective data analysed separately included only 128 fixed effects of the horse breed status (endangered/non-endangered) and the year of test. The 129 following model was used for the objective data:

$130 \quad \mathrm{y}_{\mathrm{ijklmn}}=\alpha+\mathrm{B}_{\mathrm{i}}+\mathrm{Y}_{\mathrm{j}}+\mathrm{H}_{\mathrm{k}}+\mathrm{J}_{\mathrm{l}}+\mathrm{h}_{\mathrm{m}}+\mathrm{e}_{\mathrm{ijk} k m n}$

131 where:

$132 \mathrm{y}_{\mathrm{ijkl} m n}$ - evaluation of the stallion,

$133 \alpha$ - adequate intercepts,

$134 \quad B_{i}$ - fixed effect of $(i=1,2)$ for the endangered and non-endangered breed;

$135 \mathrm{Y}_{\mathrm{j}}$ - fixed effect of the year $(\mathrm{j}=1,2,3)$ of the test;

$136 \quad \mathrm{H}_{\mathrm{k}}$ - fixed effect of obstacle height $(\mathrm{k}=100,110,120)$; 
$137 \mathrm{~J}_{1}$ - fixed effect of the successive number of the jump $(\mathrm{l}=1,2,3)$;

$138 \mathrm{~h}_{\mathrm{m}}$ - random effect of the horse $(\mathrm{m}=1, \ldots, 186)$;

$139 \mathrm{e}_{\mathrm{ijklmn}}$ - random errors.

140

141 For the subjective data the model was as follows:

$142 \mathrm{y}_{\mathrm{ijk} k}=\alpha+\mathrm{B}_{\mathrm{i}}+\mathrm{Y}_{\mathrm{j}}+\mathrm{e}_{\mathrm{ijk}}$

143 where:

$144 \mathrm{y}_{\mathrm{ijk}}$ - evaluation of the stallion,

$145 \alpha$-adequate intercepts,

$146 \mathrm{~B}_{\mathrm{i}}$ - fixed effect of $(\mathrm{i}=1,2)$ for endangered and non-endangered breed;

$147 Y_{j}$ - fixed effect of the year $(j=1,2,3)$ of the test;

$148 \mathrm{e}_{\mathrm{ijkl}}-$ random errors.

149 The interactions between main effects were tested and found not statistically significant.

150 Differences between the levels of investigated effects were tested by multiple comparisons based 151 on the all-pairs test between the least square means (LSM). For a detailed comparison of the data 152 the results of the analysis of variance were supported by the partial correlations provided by the 153 model (the MANOVA option in the Mixed procedure) for the relationships between notes and 154 parameters, as well as those between jumping parameters for separate breeds.

\section{Results}

157 The characteristics of variables were normally distributed. The mean of all subjective 158 notes was calculated individually, with the lowest of 5.5 and the highest score of 7.0 points and 159 the standard deviation of 0.9-1.9. The take-off and landing distances were $266.2 \mathrm{~cm}$ (SD 39.7) 160 and $201.8 \mathrm{~cm}$ (SD 46.5), respectively. The height to which each limb was lifted ranged from 23.9 161 to $25.9 \mathrm{~cm}$ (SD 12-14.3). The mean elevation of the body for the measured bascule points was 162 calculated in the same way to range between 122.9 and $132 \mathrm{~cm}$ (with SD 17-22). The mean head 163 angle was $27.5^{\circ}$ (SD 6.3). The mean duration of the jump was 16.6 frames (SD 2).

164 Results of the statistical analysis are presented in Table 1 for objective measurements and 165 in Table 2 for subjective performance test marks. Studied groups of horses differed statistically 
166 significantly in terms of their jumping style for the bascule points - the elevation of the withers 167 and croup $(\mathrm{p} \leq 0.001)$ and for the time of take-off $(\mathrm{p} \leq 0.05)$. The group of horses from the 168 endangered population elevated their bodies above the obstacle higher than the group of sport 169 horses (above 4\% in both variables) with the head position at the same height above the obstacle. 170 The take-off time was longer for the endangered population (about 3\%).

171 Statistically significant differences for the subjectively evaluated marks are observed for 172 the following traits: trainability, jumping under the rider $(\mathrm{p} \leq 0.001)$ and free jumping $(\mathrm{p} \leq 0.05)$ 173 evaluated based on the trainers' opinion. The non-endangered population received higher scores 174 in free jumping (about 6\%), while judges evaluated the same trait similarly. The notes for 175 jumping skills in the performance test referred to the full 100-day performance period. 176 Therefore, the trainers had a greater possibility to observe horses throughout the whole period of 177 the test. Judges and riders visit the training centre once up to three times during the test. More 178 information on jumping skills is received based on the measured objective jumping variables 179 rather than objective judging, which also seems to vary in the amount of provided information.

180 Obtained correlations support these results as well. The correlations between measured parameters and marks for jumping traits received by both groups of horses are presented in Table 3. Among 13 traits only two were judged almost in the same way in both groups - it was lifting of both front limbs. The take-off distance was significantly correlated with most evaluated traits in the endangered horses. Landing was highly significantly correlated with the free jumping evaluation score given by the judges (correlation coefficient 0.40 ) for the endangered group and only 0.09 for the other population. Correlations between free jumping and lifting of hind limbs were comparable for the scores given by the judges (approx. 0.2), but not for the trainers' notes. The correlation between the elevation of the croup and the note for jumping under a rider for the endangered group evaluated by the judges was twice as high as the respective correlations for the other horse group. The head angle and landing time received different scores in both groups as well. Most of the differences for these parameters are relatively small and seem random. These

192 discrepancies might have been caused by the awareness of the catalogue information on individual horses and by personal preferences of the judges for specific horse lines.

In the comparison of relationships within jumping parameters (Table 4) most spatial parameters have lower values of correlations between jumping parameters for the endangered horses than for the non-endangered horses. That fact means that non-endangered horses are more 
197 elastic in jumping, as the parameters are not so dependent on each other. For the temporal 198 parameters their relationships are not so obvious. The spatial parameters of jumps are timecorrelated in both groups (to a greater extent for the endangered horses), whereas for the endangered group it was with the take-off time mainly and for the other population it was with the landing time. This may also be connected with the greater potential and elasticity of the jump, as it is known that basic parameters of the jump are dependent on the quality of the take203 off.

\section{Discussion}

The horses from the endangered breed moved their trunk higher above the obstacles and either received lower marks for free jumping or did not differ in the scores based on the opinion of different evaluators. The higher elevation of the body is very often believed to be a sign of respect or even fear of obstacle. Horses are expected to jump economically - not too high above the obstacle; however, such a jumping style should be expected when sport horses are older and more experienced. The ability to recognise the height of an obstacle is considered to be an

212 important horse skill (Kampman et al. 2012). Probably such preferences caused lower horse 213 scores for free jumping in our study based on the trainers' opinion (6.65 points in the endangered group vs. 7.04 in the non-endangered group). The higher elevation of the body (about 4\%) of the endangered horses with their limbs being lifted to the same height as in the non-endangered

216 horses resulted in the endangered horses considered to be jumping higher because of insufficient

217 limb elasticity. That supported the trainers' lower opinion ( 0.4 points) on jumping skills of the 218 endangered horses. Their opinion may have also been affected by the requirements of the most 219 important jumping competitions that are conducted "against the clock". The higher trunk 220 elevation takes more time than a lower jump, so horses jumping higher need more time to clear 221 the course and may lose their competitions in the future. Such an attitude to jumping assessment 222 complied with the KWPN guide for evaluating the quality of jumping technique. Both in the 223 KWPN and in the PHBA guidelines the speed of take-off is considered a positive characteristic 224 (Kampman et al. 2012).

225 In turn, the ability to jump higher and the lightness of jump ("ease" and "willingness") 226 were the traits included in the judges' evaluation system as well. It is likely that a higher 227 elevation and a better curve of the trunk (with the head being in the same position) observed in 
228 the endangered group of horses were treated as superior jumping abilities. Thus the marks given

229 by the judges to horses jumping in that manner were slightly higher in the analysed performance

230 results, while not being statistically significant (7.13 points for the endangered group vs. 6.93 for

231 the non-endangered group).

232 The differences in scores for jumping under the rider in the trainers' opinion may be 233 associated with the fact that the Polish endangered Warmblood horses are more closely related to 234 Arabian horses, so they tend to be more temperamental and as such more difficult for riders to 235 handle. In the presented study the endangered group was evaluated higher in terms of 236 temperament - 7.97 points (SD 0.16) as compared with 7.65 (SD 0.06) for the other group (data 237 not presented in the tables, the difference statistically non-significant).

Differences in the opinions on jumping skills may also be affected by the character of 239 visual perception. The human perception is a complex process involving integration of the first and second order motion signals (e.g. luminance, contrast) from various parts of the retinal image carried by separate processing pathways. The "global motion" picture is produced from individual visual fields of neurons (Burr \& Santoro, 2001). Especially fast motion may be connected with some difficulty in the correct assessment of the 'signal' and 'noise' required to determine motion. The human perception is connected with different phenomena. For example, if the special time period between separate image stimuli is used, the eyes provide the perception of motion; similarly, a fast succession of still images of a ball within a proper distance gives the illusion of a moving ball (Steinman et al. 2000). It seems possible that expectations of the judges based on the knowledge of the horse's pedigree as well as their individual preferences based on conformation or earlier experiences may determine their perception as well. In our study the trainers gave their notes within a wider scale (2-9 points) than the judges (4-10 points), which was probably because of their more extensive experience with the tested horses. influences. Probably that is the reason why they have been developed and implemented (Koenen et al. 1995, Rustin et al. 2009, Duensing et al. 2014). Even if they do not provide the same level of accuracy as VIA methods, they may be considered an optimum tools (Duensing et al. 2014). Characterisation of traits in the descriptive scale seems to be a better option for horse evaluation in comparison with the subjective evaluation system. Unfortunately, similarly as the point score system linear scoring is also based on the judge's experience, rather than measured values. Some 
259 further studies on the objectivity of linear scoring have been conducted (Doucet 2006). 260 Additionally, three-dimensional methods have been shown to be more accurate than two-

261 dimensional ones, since they are not restricted to the calibration area (Weller et al. 2006).

262 Nevertheless, they still seem of limited use under field conditions.

263 Every system has its limitations. The subjective definition of a trait does not give the 264 same information for everybody, as judges differ in their opinions (Lewczuk, 2013). On the other 265 hand, a detailed linear description of a trait may cause the loss of important information not 266 specifically named and recorded earlier. Both evaluation systems (linear scoring vs. traditional 267 point system) may be influenced by different personal experiences of judges. In the linear system 268 all traits are described in relation to the population mean being the centre of the scale (e.g. short 269 vs. long legs; square vs. rectangular body frames), while in the point evaluation scale (from 1 very bad to 10 - excellent) the note is referred to the ideal image as perceived by the judge. In

271 both cases the evaluation depends on the experience of evaluators. Their 'population mean' as 272 well as 'the concept of a perfect horse' depend on the experience and may potentially affect the 273 actual comparisons between countries or breeds. Another complexity is related with the 274 evolution of prospects in animal breeding. Traits may be changed in the ideal standards in 275 response to the selection processes and as a consequence, in the population means. An example 276 may be provided by the horse production area. Height at the withers is just such a characteristic. 277 Straight lines between obstacles in show jumping courses with high obstacles used until the 278 1960's (Gego, 2006) favoured selection for horses that were high at the withers to enlarge the 279 scope of jumps. It changed later as the maximal jumping scope was not the main difficulty in 280 show jumping competitions. New trends in jumping course design changed conformation 281 preferences in breeding of jumping horses. Difficult lines to follow between obstacles, curves of 282 the horse's path in jumping courses created new demand for winner horses that had to be elastic, 283 smaller and easily rideable. This characteristic was not correlated with the large body frames of 284 horses bred earlier. Horses studied in our research did not differ in terms of their body frames 285 (height at the withers $-166 \mathrm{~cm}$ for the non-endangered vs. $164 \mathrm{~cm}$ for the endangered group with 286 SD of 2.31 and 2.88, respectively). Changes in the 'ideal' conformation influence the evaluation 287 in selection as well. Thus none of these systems may guarantee an absolutely reliable comparison 288 of different horse populations, especially over long time periods. From this point of view "non289 idealised" evaluation systems based on measurements and independent of the observer's 
290 experience should be used to characterise endangered jumping breeds. Correlations between 291 jumping parameters obtained in our study also underline the need for more precisely defined 292 horse characteristics, as they show differences in the horse jumping technique not reflected in the 293 judge notes. The level of the correlation coefficient presented in the study is comparable with the 294 results for Polish warmbloods calculated for all breeds (Janczarek et al. 2013); however, a 295 detailed comparison is not possible as different types of parameters were studied (angular vs. 296 linear).

297 Detailed and precise methods, although time-consuming, are employed in current horse 298 breeding research to find new genetic mutations responsible for specific traits of the endangered 299 horse population (Kristjansson et al. 2016). However, the genomic tool may be only as detailed 300 and accurate as the phenotypic data used for the primary association analysis. The discrepancy in 301 the results of genome mapping studies may reflect the variability in phenotypic criteria (McCoy 302 et al. 2016). This provides a promising future for precision phenotyping. Using subjective marks, 303 e.g. free jumping studied in our paper, may result in confusing results when traits are denoted by 304 ambiguous terms. The functional nature of the breeding goal is always the main aim for horse 305 breeding, including also endangered breeds (Weber, 2005). Monitoring of horses constituting the 306 dressage genetic resource pool facilitates introduction of particular sires into the programme 307 (Valera et al. 2013). The same should apply to endangered horse populations used in jumping. 308 309 experienced evaluators were evidenced and clarified based on the jumping variables measured using the video image analysis. Methods based on objective measurements provide precise characteristics for each breed and seem particularly important for the present day precise

317 livestock strategies. Detailed characteristics of jumping performance for endangered horse 318 breeds should be provided. 
321 References:

322 Borowska A, Szwaczkowski T, 2015. Pedigree analysis of Polish warmblood horses

323 participating in riding performance tests. Can J Anim Sci 95:21-29.

324 Burr D, Santoro L, 2001. Temporal integration of optic flow, measured by contrast and 325 coherence thresholds. Vision Res 41:1891-1899.

326 Charlesworth D, Willis JH, 2009. The genetics of inbreeding depression. Nat Rev Gen 10:783327796.

328 Curik I, Zechner P, Sölkner J, Achmann R, Bodo I, Dove P, Kavar T, Marti E, Brem G, 2003. 329 Inbreeding, microsatellite heterozygosity and morphological traits in Lipizzan horses $\quad J$

330 Hered 94: 125-132.

331 Duensing J, Stock KF, Krieter J, 2014. Implementation and prospects of linear profiling in 332 the Warmblood horse. J Equine Vet Sci 34: 360-368.

333 Doucet M. 2007. Présentation et évaluation d'une méthode de mesure morphométrique en trois dimensions. PhD Thesis École Nationale Veterinaire D’Alfort.

Ducro BJ, Bovenhuis H, Neuteboom M, Hellinga I, 2006. Genetic diversity in the Dutch 337 Friesian horse. In: Proceedings of the 8th World Congress on Genetics Applied to 2006 pp. 08-03.

ERFP. SUBSIBREED, 2014. Overview and assessment of support measures for endangered livestock breeds. Eds. Kompan D., Klopčič M., Martyniuk E. European Regional

342 Focal Point for Animal Genetic Resources.

343 Gego A, 2006. Course design, 1st edition. J.A. Allen, London, UK.

344 Janczarek I, 2011. Obiektywizacja metod oceny skoków luzem młodych ogierów półkrwi.

345 Ed. UP Lublin pp.1-148.

346 Janczarek I, Stachurska A, Wilk I, 2013. Correlation between kinematic parameters of the free jumping horse in the first approach stride. Acta Agri Scand, sec. A - Anim Sci 63(2),

349 Kampman I, Van Deurzen I, Loeffen C, Dekker C, Monas S, 2012. The KWPN-horse. 350 Selection for performance. Ed. KWPN pp. 1-98. 
351 Koenen EPC, Van Veldhuizen AE, Brascamp EW, 1995. Genetic parameters of linear scored

352 conformation traits and their relation to dressage and show-jumping performance in the

353 Dutch Warmblood Riding Horse population. Livest Prod Sci 43: 85-94.

354 Kjöllerström HJ, Gama LT, Oom MM, 2015. Impact of inbreeding on fitness-related traits in 355 the highly threatened Sorraia horse breed. Livest Sci 180:84-89.

356 Kristjansson T, Bjornsdottir S, Sigurdsson A, Crevier-Denoix N, Pourcelot P, Arnason T, 2013. 357 Objective quantification of conformation of the Icelandic horse based on 3-D video morphometric measurements. Livest Sci 158:12-23.

Kristjansson T, Bjornsdottir S, Albertsdóttir E, Sigurdsson A, Pourcelot P, Crevier-Denoix N,

360 Arnason T, 2016. Association of conformation and riding ability in Icelandic horses. Livest

361 Sci 189:91-101

362 Leroy G, 2014. Inbreeding depression in livestock species: review and metaanalysis. Anim 363 Gen 45: 618-628.

364

365

366

367

368

369

370

371

372

373

374

375

376

377

378

379

380

Lewczuk D, 2008. Analiza systemu sędziowania zdolności skokowych koni w skokach luzem za pomocą komputerowej analizy obrazu. In Polish. Ed. IGHZ PAN Jastrzębiec pp.1-76

Lewczuk D, 2013. Effect of the judge and definition of the trait for horse free jumping evaluation. Archiv Tierz 56 64: 638-649.

McCoy A, Beeson SK, Splan RK, Lykkjen S, Ralston SL, Mickelson JR, McCue ME, 2016. Identification and validation of risk loci for osteochondrosis in standardbreds. BMC

Genomics 17:41, doi: 10.1186/s12864-016-2385-z

Pikuła R, Grzesiak W, Zaborski D, Werkowska W, 2017. An analysis of the inbreeding level of Holstein stallions presented for classification in 2003-2012. Acta Sci. Pol.

Zootechnica 16:2:35-38.

Rustin M, Janssens S, Buys N, Gengler N, 2009. Multi-trait animal model estimation of genetic parameters for linear type and gait traits in the Belgian warmblood horse. J Anim Breed Gen 126: 378-386.

Sairanen J, Nivola K, Katila T, Virtala AM, Ojala M, 2009. Effects of inbreeding and other genetic components on equine fertility. Animal 3:1662-1672.

Steinman RM, Pizlo Z, Pizlo FJ, 2000. Phi is not beta, and why Wertheimer's discovery launched the Gestalt revolution. Vision Res 40: 2257-2264. 
381 Solé M, Valera M, Gómez MD, Cervantes I, Fernández J, 2013a. Implementation of

382 Optimum Contributions Selection in endangered local breeds: the case of the Menorca

383 Horse population. J Anim Breed Gen 130: 218-226

384 Solé M, Santos R, Gómez MD, Galisteo AM, Valera M, 2013b. Evaluation of conformation

385 against traits associated with dressage ability in unridden Iberian horses at the trot. Res

386 Vet Sci 95:660-666.

387 Solé M, Gómez MD, Galisteo AM, Santos R, Valera M, 2013c. Kinematic characterization of the Menorca Horse at the Walk and the Trot: Influence of Hind Limb Pastern Angle. J

389 Equine Vet Sci 33:726-732.

390 Weber M, 2005. Betreuung von einheimischen vom Aussterben bedrother Rassen dargestellt

391

392

393

394

395

396

397

398

399

400

401

402

403

404 am Beispiel der Schwarzwälder Füchse in Baden-Württemberg. 4.Pferde-Workshop, Ed. CAU Institute für Tierzucht und Tierhaltung Kiel, Germany 22-23.02.2005 pp.134 140.

Weller R, Pfau T, Babbage D, Brittin E, May SA, Wilson AM, 2006. Reliability of conformational measurements in the horse using a three-dimensional motion analysis system. Equine Vet J 38:610-615.

Valera M, Solé M, Gómez MD, Molina A, Peña F, 2013. Analyses of conformational performance differentiation among functional breeding goals in the Menorca horse breed. Archiv Tierz 56 37:367-379.

Vicente AA, Carolino N, Gama LT, 2012. Genetic diversity in the Lusitano horse breed assessed by pedigree analysis. Livest Sci 148:16-25.

Vostrá-Vydrová H, Vostrý L, Hofmanová B, Krupa E, Zavadilová L, 2016. Pedigree analysis of the endangered Old Kladruber horse population. Livest Sci, 185:17-23. 


\section{Table $\mathbf{1}$ (on next page)}

The least squares means (LSM) and standard errors (SE) for the effect of horse endangerment status on the objective jumping variables evaluated by video image analysis on stallions performance tests 
1 Table 1.

2 The least squares means (LSM) and standard errors (SE) for the effect of horse endangerment status on

3 the objective jumping variables evaluated by video image analysis on stallions performance tests

Status of endangerment

LSM (SE)

Traits

\begin{tabular}{|c|c|}
\hline $\begin{array}{l}\text { Non-endangered } \\
(\mathrm{N}=159)\end{array}$ & $\begin{array}{l}\text { Endangered } \\
(\mathrm{N}=27)\end{array}$ \\
\hline $275.3(13.4)$ & $279.2(14,1)$ \\
\hline $185.3(15.3)$ & $182.2(16.1)$ \\
\hline $21.09(3.7)$ & $20.1(3.9)$ \\
\hline $21.1(3.7)$ & $19.4(3.9)$ \\
\hline $23.0(4.8)$ & $26.0(5.0)$ \\
\hline $26.8(4.8)$ & $28.0(5.0)$ \\
\hline $115.5(5.0)^{\mathrm{A}}$ & $120.6(5.4)^{\mathrm{A}}$ \\
\hline $126.6(5.4)^{\mathrm{A}}$ & $132.3(5.7)^{\mathrm{A}}$ \\
\hline $124.4(6.2)$ & $125.8(6.6)$ \\
\hline $28.6(2.1)$ & $28.6(2.2)$ \\
\hline $7.87(0.37)^{a}$ & $8.14(0.39)^{a}$ \\
\hline $7.91(0.33)$ & $7.88(0.34)$ \\
\hline $16.78(0.54)$ & $17.02(0.56)$ \\
\hline
\end{tabular}

Take off $(\mathrm{cm})$

Landing $(\mathrm{cm})$

Lifting of front right $(\mathrm{cm})$

Lifting of front left $(\mathrm{cm})$

Lifting of hind right $(\mathrm{cm})$

Lifting of hind left $(\mathrm{cm})$

Elevation of croup (cm)

Elevation of withers $(\mathrm{cm})$

Elevation of head $(\mathrm{cm})$

Head angle $\left(^{\circ}\right)$

Take off time (frames)

Landing time (frames)

$16.78(0.54)$

$17.02(0.56)$

Total time (frames)

A a - Differences in rows statistically significant for $\mathrm{P} \leq 0.001$ capitals. for $\mathrm{P} \leq 0.05$ small letters

\section{5}

6 


\section{Table 2 (on next page)}

The least squares means (LSM) and standard errors (SE) for the effect of horse endangerment status on subjective jumping evaluations on stallions performance tests 
1 Table 2. The least squares means (LSM) and standard errors (SE) for the effect of horse endangerment 2 status on subjective jumping evaluations on stallions performance tests

Status of endangerment

Trait / evaluator

$\operatorname{LSM}(\mathrm{SE})$

(points)

\begin{tabular}{ll}
\hline Non-endangered & Endangered \\
$(\mathrm{N}=159)$ & $(\mathrm{N}=27)$
\end{tabular}

Trainability / trainer

$7.06(0.08)^{\mathrm{A}}$

$6.54(0.18)^{\mathrm{A}}$

Free jumping / trainer

$7.04(0.07)^{\mathrm{a}}$

$6.65(0.17)^{\mathrm{a}}$

Jumping with the rider / trainer

$6.74(0.07)^{\mathrm{A}}$

$6.15(0.18){ }^{\mathrm{A}}$

Free jumping / judges

$6.93(0.07)$

$7.13(0.17)$

Jumping with the rider / judges

$6.87(0.07)$

$6.87(0.18)$

Rideability jumping / riders

$6.00(0.13)$

$5.54(0.32)$

3 A a - Differences in rows statistically significant for $\mathrm{P} \leq 0.001$ capitals. for $\mathrm{P} \leq 0.05$ small letters

4

5

6

7 


\section{Table 3(on next page)}

- The correlations between measured parameters and results of evaluation for endangered and non-endangered groups of horses (statistically significant for $p<0.05$ in bold) 
1 Table 3. The correlations between measured parameters and results of evaluation for endangered and non-endangered groups of horses (statistically significant for $\mathrm{p}<0.05$ in bold)

Performance traits evaluated by trainers $-\mathrm{T}$. judges $-\mathrm{J}$ and riders $-\mathrm{R}$

\begin{tabular}{|c|c|c|c|c|c|c|c|}
\hline Jumping trait & Breed status & 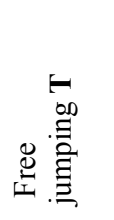 & 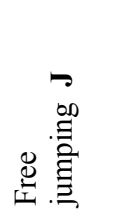 & 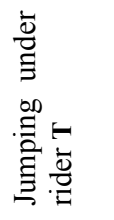 & 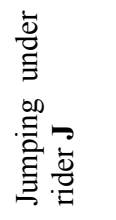 & 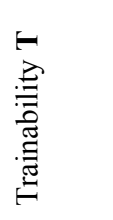 & 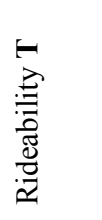 \\
\hline \multirow[t]{2}{*}{ Take off $(\mathrm{cm})$} & endangered & 0.08 & 0.13 & 0.16 & 0.24 & 0.18 & 0.17 \\
\hline & non-endangered & 0.01 & 0.15 & -0.02 & 0.13 & -0.06 & 0.01 \\
\hline \multirow[t]{2}{*}{ Landing $(\mathrm{cm})$} & endangered & 0.05 & 0.40 & 0.15 & 0.16 & -0.03 & 0.19 \\
\hline & non-endangered & 0.02 & 0.09 & -0.03 & 0.06 & -0.03 & -0.04 \\
\hline \multirow[t]{2}{*}{ Lifting of front right $(\mathrm{cm})$} & endangered & 0.25 & 0.43 & 0.40 & 0.40 & 0.26 & 0.23 \\
\hline & non-endangered & 0.29 & 0.30 & 0.23 & 0.25 & 0.25 & 0.19 \\
\hline \multirow[t]{2}{*}{ Lifting of front left $(\mathrm{cm})$} & endangered & 0.23 & 0.33 & 0.22 & 0.30 & 0.09 & 0.23 \\
\hline & non-endangered & 0.27 & 0.29 & 0.23 & 0.22 & 0.23 & 0.16 \\
\hline \multirow[t]{2}{*}{ Lifting of hind right $(\mathrm{cm})$} & endangered & 0.07 & 0.35 & 0.27 & 0.38 & 0.11 & 0.21 \\
\hline & non-endangered & 0.20 & 0.27 & 0.17 & 0.21 & 0.16 & 0.11 \\
\hline \multirow[t]{2}{*}{ Lifting of hind left $(\mathrm{cm})$} & endangered & 0.08 & 0.34 & 0.18 & 0.32 & 0.02 & 0.19 \\
\hline & non-endangered & 0.22 & 0.29 & 0.22 & 0.20 & 0.20 & 0.07 \\
\hline \multirow[t]{2}{*}{ Elevation of croup $(\mathrm{cm})$} & endangered & 0.13 & 0.18 & 0.19 & 0.31 & 0.11 & 0.04 \\
\hline & non-endangered & 0.10 & 0.21 & 0.06 & 0.13 & 0.05 & -0.02 \\
\hline \multirow[t]{2}{*}{ Elevation of withers $(\mathrm{cm})$} & endangered & 0.11 & 0.21 & 0.18 & 0.28 & 0.11 & 0.07 \\
\hline & non-endangered & 0.10 & 0.20 & 0.04 & 0.12 & 0.02 & -0.03 \\
\hline \multirow[t]{2}{*}{ Elevation of head $(\mathrm{cm})$} & endangered & -0.15 & -0.12 & -0.09 & 0.07 & 0.04 & -0.10 \\
\hline & non-endangered & -0.08 & -0.03 & -0.14 & -0.08 & -0.09 & -0.17 \\
\hline \multirow[t]{2}{*}{ Head angle $\left(^{\circ}\right)$} & endangered & -0.06 & -0.24 & -0.24 & -0.10 & -0.04 & -0.34 \\
\hline & non-endangered & -0.18 & -0.14 & -0.21 & -0.13 & -0.19 & -0.23 \\
\hline \multirow[t]{2}{*}{ Take off time (frames) } & endangered & 0.20 & -0.17 & 0.19 & 0.23 & 0.47 & 0.01 \\
\hline & non-endangered & 0.11 & 0.13 & 0.10 & 0.11 & 0.09 & 0.09 \\
\hline \multirow[t]{2}{*}{ Landing time (frames) } & endangered & 0.06 & 0.16 & 0.18 & 0.30 & 0.04 & 0.01 \\
\hline & non-endangered & 0.29 & 0.32 & 0.21 & 0.22 & 0.15 & 0.16 \\
\hline \multirow[t]{2}{*}{ Total time (frames) } & endangered & 0.17 & 0.22 & 0.25 & 0.35 & 0.33 & -0.01 \\
\hline & non-endangered & 0.25 & 0.29 & 0.19 & 0.21 & 0.14 & 0.16 \\
\hline
\end{tabular}




\section{Table 4 (on next page)}

The correlations between measured parameters for endangered and non-endangered groups of horses (statistically significant for $p<0.05$ in bold) 
1 Table 4. The correlations between measured parameters for endangered and non-endangered groups of 2 horses (statistically significant for $\mathrm{p}<0.05$ in bold)

\begin{tabular}{|c|c|c|c|c|c|c|c|c|c|c|c|c|c|c|}
\hline \multirow[b]{2}{*}{ Jumping trait } & \multirow[b]{2}{*}{ Breed status } & \multicolumn{13}{|c|}{ Jumping trait } \\
\hline & & 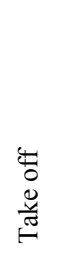 & 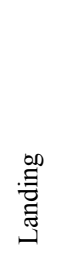 & 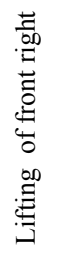 & 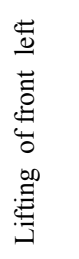 & 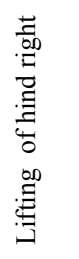 & 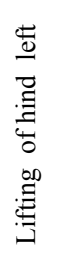 & 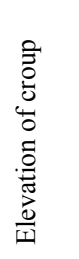 &  & 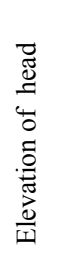 & 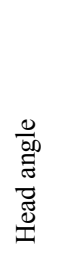 & 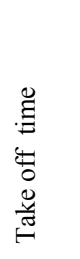 & 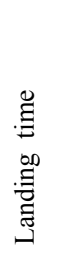 & 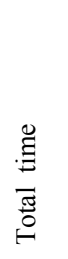 \\
\hline \multirow[t]{2}{*}{ Take off $(\mathrm{cm})$} & endangered & $\mathrm{X}$ & 0.32 & 0.48 & 0.63 & 0.58 & 0.52 & 0.62 & 0.63 & 0.45 & -.26 & 0.48 & 0.09 & 0.38 \\
\hline & non-endangered & $\mathrm{X}$ & 0.13 & 0.14 & 0.22 & -.08 & 0.07 & 0.54 & 0.53 & 0.37 & 0.20 & 0.33 & 0.14 & 0.32 \\
\hline \multirow[t]{2}{*}{ Landing (cm) } & endangered & 0.32 & $\mathrm{X}$ & 0.47 & 0.48 & 0.55 & 0.58 & 0.59 & 0.58 & 0.30 & -.13 & 0.23 & 0.13 & 0.25 \\
\hline & non-endangered & 0.13 & $\mathrm{X}$ & 0.15 & 0.15 & 0.11 & 0.16 & 0.38 & 0.43 & 0.35 & -.04 & -.06 & 0.12 & 0.13 \\
\hline \multirow{2}{*}{ Lifting of front right $(\mathrm{cm})$} & endangered & 0.48 & 0.47 & $\mathrm{X}$ & 0.85 & 0.77 & 0.77 & 0.72 & 0.70 & 0.33 & -.17 & 0.44 & 0.26 & 0.46 \\
\hline & non-endangered & 0.14 & 0.15 & $\mathrm{X}$ & 0.66 & 0.25 & 0.28 & 0.48 & 0.48 & 0.33 & -.15 & 0.31 & 0.34 & 0.42 \\
\hline \multirow{2}{*}{ Lifting of front left $(\mathrm{cm})$} & endangered & 0.63 & 0.48 & 0.85 & $X$ & 0.76 & 0.76 & 0.77 & 0.70 & 0.33 & -.17 & 0.38 & 0.26 & 0.34 \\
\hline & non-endangered & 0.22 & 0.15 & 0.66 & $\mathrm{X}$ & 0.30 & 0.29 & 0.54 & 0.54 & 0.41 & -.13 & 0.31 & 0.36 & 0.43 \\
\hline \multirow[t]{2}{*}{ Lifting of hind right $(\mathrm{cm})$} & endangered & 0.58 & 0.55 & 0.77 & 0.76 & $\mathrm{X}$ & 0.96 & 0.76 & 0.77 & 0.37 & -.19 & 0.39 & 0.43 & 0.54 \\
\hline & non-endangered & -.08 & 0.11 & 0.25 & 0.30 & $\mathrm{X}$ & 0.91 & 0.30 & 0.25 & 0.03 & -.19 & 0.03 & 0.40 & 0.26 \\
\hline \multirow[t]{2}{*}{ Lifting of hind left $(\mathrm{cm})$} & endangered & 0.52 & 0.58 & 0.77 & 0.76 & 0.96 & $\mathrm{X}$ & 0.77 & 0.77 & 0.34 & -.13 & 0.32 & 0.37 & 0.46 \\
\hline & non-endangered & 0.07 & 0.16 & 0.28 & 0.29 & 0.91 & $\mathrm{X}$ & 0.37 & 0.35 & 0.08 & -.20 & 0.07 & 0.41 & 0.30 \\
\hline \multirow[t]{2}{*}{ Elevation of croup (cm) } & endangered & 0.62 & 0.59 & 0.72 & 0.77 & 0.76 & 0.77 & $\mathbf{X}$ & 0.97 & 0.65 & -.01 & 0.54 & 0.37 & 0.60 \\
\hline & non-endangered & 0.54 & 0.38 & 0.48 & 0.54 & 0.30 & 0.37 & $\mathbf{X}$ & 0.96 & 0.72 & -.05 & 0.32 & 0.26 & 0.38 \\
\hline \multirow[t]{2}{*}{ Elevation of withers $(\mathrm{cm})$} & endangered & 0.63 & 0.58 & 0.70 & 0.70 & 0.77 & 0.77 & 0.97 & $\mathrm{X}$ & 0.63 & -.12 & 0.48 & 0.43 & 0.60 \\
\hline & non-endangered & 0.53 & 0.43 & 0.48 & 0.54 & 0.25 & 0.35 & 0.96 & $\mathrm{X}$ & 0.70 & -.09 & 0.30 & 0.30 & 0.39 \\
\hline \multirow[t]{2}{*}{ Elevation of head $(\mathrm{cm})$} & endangered & 0.45 & 0.30 & 0.33 & 0.39 & 0.37 & 0.34 & 0.65 & 0.63 & $\mathrm{X}$ & 0.34 & 0.46 & 0.10 & 0.39 \\
\hline & non-endangered & 0.38 & 0.35 & 0.33 & 0.41 & 0.03 & 0.08 & 0.72 & 0.70 & $\mathrm{X}$ & 0.25 & 0.17 & 0.09 & 0.17 \\
\hline \multirow[t]{2}{*}{ Head angle $\left(^{\circ}\right)$} & endangered & -.26 & -.13 & -.17 & -.17 & -.19 & -.13 & 0.01 & -.12 & 0.34 & $\mathrm{X}$ & 0.06 & -.19 & -.09 \\
\hline & non-endangered & 0.20 & -.04 & -.15 & -.13 & -.19 & -.20 & -.05 & -.09 & 0.25 & $\mathrm{X}$ & -.01 & -.19 & -.13 \\
\hline \multirow[t]{2}{*}{ Take off time (frames) } & endangered & 0.48 & 0.23 & 0.44 & 0.38 & 0.39 & 0.32 & 0.54 & 0.48 & 0.48 & 0.06 & $X$ & 0.13 & 0.74 \\
\hline & non-endangered & 0.33 & -.06 & 0.31 & 0.31 & -.03 & -.07 & 0.32 & 0.30 & 0.17 & -.01 & $\mathrm{X}$ & 0.19 & 0.80 \\
\hline \multirow[t]{2}{*}{ Landing time (frames) } & endangered & 0.09 & 0.13 & 0.26 & 0.26 & 0.43 & 0.37 & 0.37 & 0.43 & 0.10 & -.19 & 0.13 & $\mathrm{X}$ & 0.76 \\
\hline & non-endangered & 0.14 & 0.12 & 0.34 & 0.36 & 0.40 & 0.41 & 0.26 & 0.30 & 0.09 & -.19 & 0.19 & $\mathrm{X}$ & 0.73 \\
\hline \multirow[t]{2}{*}{ Total time (frames) } & endangered & 0.38 & 0.25 & 0.46 & 0.36 & 0.54 & 0.46 & 0.60 & 0.60 & 0.39 & -.09 & 0.74 & 0.76 & $X$ \\
\hline & non-endangered & 0.32 & 0.13 & 0.42 & 0.43 & 0.26 & 0.30 & 0.38 & 0.39 & 0.17 & -.13 & 0.80 & 0.73 & $X$ \\
\hline
\end{tabular}


